\title{
Soil Respiration in Drying of an Organic Soil
}

\author{
Zofia Fischer' ${ }^{1}$, Pavel Blažka2* \\ ${ }^{1}$ Department of Biotechnology and Environment, John Paul II, Catholic University of Lublin, Lublin, Poland \\ ${ }^{2}$ Department of Science, University of South Bohemia, České Budějovice, Czech \\ Email: pavelblazka@seznam.cz, zofiaf@plusnet.pl
}

Received 6 August 2015; accepted 28 August 2015; published 31 August 2015

Copyright (c) 2015 by authors and Scientific Research Publishing Inc.

This work is licensed under the Creative Commons Attribution International License (CC BY). http://creativecommons.org/licenses/by/4.0/

(c) () Open Access

\begin{abstract}
Drying of soil was linearly related to time, soil volume decreased and ratio of air within the soils increased. Respiration was related with decreasing humidity, storage of $\mathrm{CO}_{2}$ in soil water results in $\mathrm{RQ}<0.5$ in the larger soil items at least for a while. Rate of drying decreased in the second part of the process. $\mathrm{RQ}$ increased as the $\mathrm{CO}_{2}$ stored was aerated when its solvent-water evaporated and access of air into the soil increased; eventually $R Q=1.0$ in the last days of the experiment. Respiration of the experimental soil stopped when GWC reached 0.15 . $\Sigma R Q$ for the whole process is about 0.7 , a bit higher in experiments with less soil suggesting less anoxia.
\end{abstract}

\section{Keywords}

\section{$\mathrm{RQ}$, Anoxia, Storage of $\mathrm{CO}_{2}$, Changes of Soil Volume}

\section{Introduction}

In the present contribution our original idea was to study process of drying more in detail. Soils in natural settings are changing; this may be approached not only in field work, but also in lab experiments, where the conditions may be set more accurately and less rely on unpredictable weather etc. and show how they are reflected in the process, particularly in soil respiration. During the work we realized however, that some concepts are generally not quite clear or understood and we propose some clarification, both by pointing to literature not frequently referred in soil science and/or through experimental design.

Respiration was/is considered as a general measure of soil activity (somewhat mystical statement, preferably of soil organisms), recirculation of nutrients from plant residues, while drying of soil is associated with wet and dry periods, seasons, hence more recently with global changes.

Soil respiration was studied many times; the literature on it is quite extensive [1]-[3]. It is based both on field measurements and on laboratory experimentation. The latter is mostly associated with sieving to get more re-

${ }^{*}$ Corresponding author. 
producible results, and also with mixing and thus aeration of the soil material. We tried to overcome the sieving effect by slightly compressing the sieved soil by hand [4]. We have seen no other reference on the effect of compression in literature. We want to however first make some introductory comments to the subject respiration. The word respiration is historically (since $18^{\text {th }}$ century) associated primarily with oxygen consumption by men and animals, more recently in biochemistry with oxidation of protons to water in the oxidative phosphorylation pathway as part of the general scheme of energy metabolism in most organisms, prokaryotes and eukaryotes; plants, animals and fungi-except only obligatory anaerobes [5]-[7]. Respiration is a heterotrophic process and also root respiration is not autotrophic e.g. [3], [8] though it is run by organisms, which largely live autotrophically; all plants are however heterotrophs at night. Soil respiration, meaning respiration of the whole soil community, was introduced later (first half of $20^{\text {th }}$ century—Suchtelen [9] was probably among the first). Respiration is anyway a biological process; all biological principles are to be included, not discarded, but it is also a part of soil biology, a composite science as soil physics, biochemistry, geology etc.; all parts have to be observed with the same scrutiny, accuracy and respect to achieve real progress in soil science as a whole.

The sequence/wording "anaerobic respiration" (meaning reduction of e.g. nitrate, nitrite or sulfate replacing dioxygen as proton acceptor) is used quite frequently, though it is not particularly accurate, nitrate and sulfate reduction or proton acceptance would be more to the point, but may be perhaps tolerated.

Respiratory production of carbon dioxide occurs largely in the tricarboxylic acids cycle, is associated through oxidative phosphorylation with oxygen consumption, their ratio in terms of absolute values of moles or volumes is the respiratory quotient $\left(\mathrm{RQ}=\right.$ [production $\left.\mathrm{CO}_{2}\right] /\left[\right.$ consumption $\left.\mathrm{O}_{2}\right]$ ).

Introduction of reliable IR non-dispersive spectrophotometers ( In fact already 1850 paper based on $\mathrm{CO}_{2}$ ) enabling measurements of small concentrations and changes of carbon dioxide concentrations to soil science provoked some shifts in terminology; soil biological activity—measured as production of carbon dioxide-is now quite frequently referred as soil respiration e.g. [2] [8] [10], most clearly formulated by Gaumont-Guay et al. [11] ("The efflux of carbon dioxide $\left(\mathrm{CO}_{2}\right)$ from the soil, referred to hereafter as soil respiration..."). There are however quite a few sources of carbon dioxide in soils, besides processes involving primarily inorganic substrates, e.g. acidification of carbonates by acids [12], there is also a number of fermentation types occurring when oxygen availability is limited. Both respiration and fermentation are the only processes providing energy to organisms (as macroergic P-bonds [ P], largely ATP). Fermentation in soils contemporary with respiration is apparently quite frequent, particularly when soils become wet and both involve also consumption of some substrate(s); it is therefore surprising, if there is no information on SOM given, particularly in dry environment where very low SOM may be expected e.g. [13]. Carbon dioxide produced in fermentation is associated with much smaller gain in useful energy (about 3 to 4-times) compared to respiration. Respiration supplemented by fermentation is likely the most frequent situation in soils with inadequate oxygen availability; though even low partial tensions of $\mathrm{O}_{2}$ are mostly adequate for microorganisms. This results in $\mathrm{RQ} \geq 1$ and decreasing production of $\sim \mathrm{P}$. On the other hand, many products of fermentations may be readily available substrates in respiration, if dioxygen becomes available again. This is also reflected in the interpretation of the RQ. Very often limits for $\mathrm{RQ}$ are given e.g. within 0.7 till 1.3. In fact in anaerobes (obligatory or facultative, microbial or eukaryotic) RQ may be much higher (e.g. $>10)$, in strict anoxia it cannot be defined at all, as dividing by $0\left(\mathrm{O}_{2}\right.$ consumption) is a prohibited math operation. Two most important types of fermentation for soil may be lactic and ethanolic (alcoholic). While respiration of lactate and many other products of fermentation (including e.g. acetate) results in $\mathrm{RQ}=1$, like most carbohydrates; for catabolism of ethanol $\mathrm{RQ}=0.57$; in reduction of methane $\mathrm{RQ}=0.50$. Efflux of $\mathrm{CO}_{2}$ is in fact a mix of respiration, fermentation and abiotic processes leading to absorption or release of $\mathrm{CO}_{2}$. Field measurements of $\mathrm{CO}_{2}$ release to the atmosphere are useful particularly for understanding of the role of soils in the global carbon cycle. Experimental conditions (e.g., participation of autotrophs, soil humidity, differences of temperature between the "dome" and the neighboring free area...), are however to be thoroughly specified and the $\mathrm{CO}_{2}$ efflux is not considered as soil respiration.

In soil literature retention of $\mathrm{CO}_{2}$ in soil water due its high solubility (distribution coefficient air/water = approx 1 compared to dioxygen 0.03 ) is mentioned only exceptionally. In soils with $\mathrm{pH}>4$ dissolved bicarbonate becomes the dominating form of the carbonate system [14]. What we measure by any instrument is the apparent production of $\mathrm{CO}_{2}$ and RQ modified by diffusion and solubility interference. RQ is a ratio, relationship between the differences of the two components and their ratio are thus non-linear, rather exponential. Jenkins and Adams [15] are thus not correct in saying "RQ is free of empirical assumptions...", Araujo et al. [16] in accepting without comment measured $\mathrm{RQ}$ in the range $\mathrm{RQ}=0.2$ till 1.5 depending on the soil degradation level. On the 
low side remediation of hydrocarbon degradation of soils results in low RQ [17], again below the theoretical limit 0.65 for hexadecane; methane is the most reduced hydrocarbon, its oxidation (assuming only one process) results in $\mathrm{RQ}=0.5$; this should be considered as the low limit of acceptable RQ data. On the other side of possible range synthesis of lipids from carbohydrates are sometimes considered with $\mathrm{RQ} \approx 1.3$ as possible maximum. It is probably correct for respiration; we must however expect hypoxic or anaerobic conditions particularly in wet soils. Soil organisms are forced to get additional energy to what they get from decreased or even stopped respiration through some fermentation; with prevailing fermentation RQ may be well over 10. In deep anoxia $\mathrm{RQ}$ cannot be calculated at all, as $\mathrm{CO}_{2}$ is produced, but there is no oxygen consumption, division by 0 is a prohibited math operation. Let us just remind summed equation of ethanolic fermentation:

$$
\mathrm{C}_{6} \mathrm{H}_{12} \mathrm{O}_{6}=2 \mathrm{CH}_{3} \cdot \mathrm{CH}_{2} \mathrm{OH}+2 \mathrm{CO}_{2}
$$

Being aware of interferences in measurements is particularly important in studies of processes, like various kinds of acclimation to changing temperature and humidity or in the budget of a process.

We want to analyze particular parts of the drying process, not only desiccation, but also changes of soil volume, access of air/oxygen to soil aggregates, storage capacity for $\mathrm{CO}_{2}$ within the soil etc. and their impact on measured respiration data. This applies both to laboratory and field setups and involves size of soil items in both. Our soil is to some extent exceptional in high SOM content (around $50 \%$ of dry weight), many relationships studied in less organic soils need not to be applicable, also some of our conclusions are necessarily not of general use.

Drying of soils is a natural part of regular seasonal events, in observations and/or experiments many papers tend to limit themselves to just momentarily flashes or steady states; we tried however to estimate the budget of the drying process to go through different situations, states of the soil, get rid of many obstacles in getting real metabolic data. Incidentally, we came across low rates, their statistical treatment and time scales.

\section{Material and Methods}

\subsection{The Site and Soil Sampling}

The location is on the northern outskirts of the city of Warsaw (Poland). Geographic coordinates are: $52^{\circ} 20^{\prime} 212$ N, $020^{\circ} 51^{\prime 2} 260$ E, elevation $81 \mathrm{~m}$. Refer to Blazka and Fischer [18]. The aim of the study is understands of mechanisms of drying through laboratory experimentation and not description of a particular locality. We used the soil for experiments as a laboratory model. The soil is highly organic; nearly $50 \% \mathrm{LOI}$, most of the mineral fraction is sand. It comes from a wet site in a dense forest, from the very active A1 zone, depth about $10 \mathrm{~cm}$ below surface, it was $5 \mathrm{~mm}$ sieved. We got our samples respecting suggestions by Carter and Gregorich [19].

\subsection{Laboratory Analyses}

\subsubsection{Humidity}

(GWC—gravimetric water content, WHC—water holding capacity, dm—dry mass).

Our procedure was based essentially on Grace et al., Priha and Smolander [20] [21] with minor modifications [18]. GWC and other contents are given as ratios, but not \%. Dry mass was determined by drying at $110^{\circ} \mathrm{C}$ to constant weight.

\subsubsection{Soil Organic Matter (SOM and Density)}

SOM was estimated as loss of weight in ignition to constant weight (LOI) at $500^{\circ} \mathrm{C}$ on selected samples. Mean densities of SOM $(\rho=1.3)$ and of the mineral fraction of dry weight $(\rho=2.65)$, are from Ilsted et al. [4] and many others.

Organic matter $=$ LOI was between 0.45 and 0.50 .

$\rho($ soil $)=($ LOI $* 1.30+(1-$ LOI $) * 2.65=1.96$.

\subsubsection{Respiration}

(OCD—oxygen consumption, $\mathrm{PCO}_{2}$ - production of $\mathrm{CO}_{2}$, RQ—respiratory quotient).

We used the volumetric method with the Scholander type respirometer to get both the oxygen consumption and carbon dioxide production. The capacity of its cylindrical flasks is $50 \mathrm{ml}$ (inside radius $\mathrm{r}=2 \mathrm{~cm}, \mathrm{~V}=4 \mathrm{~cm}^{2}$ ) and we refer data as $\mu \mathrm{l} \cdot \mathrm{g}^{-1}$ (dry mass) $\cdot \mathrm{h}^{-1}$. Each experimental series consisted of two parts. In the first, without 
hydroxide in the flasks, changes in the volumes were recorded mostly for 5 hours, this gave the sum of $\mathrm{CO}_{2}$ changes and $\mathrm{O}_{2}$ consumption, in the second part after placing filter paper soaked with $\mathrm{NaOH}$ solution into the respirometric chamber, we recorded the oxygen consumption (OCD) for another 5 hours interval, readings each 30 minutes. This involves assumption of slow rates of metabolic changes. The bath temperature was $17.5^{\circ} \mathrm{C}$. Sensitivity of the volumetric respirometer is effectively not much worse $\left(<0.1 \mu \mathrm{lgas} \cdot \mathrm{g}^{-1} \cdot \mathrm{hour}^{-1}\right)$ than of the IR meters, though rates of providing data are not comparable.

While data of the second part were the OCD, $\mathrm{PCO}_{2}$ was calculated as first reading (without hydroxide) + second reading (with hydroxide), respecting the signs in readings and calculations. We then plotted the results against time of readings, the slope coefficient of the regression $\left(\beta_{1}\right)$ was the rate $\left(\mathrm{O}_{2}\right.$ consumption-OCD or $\mathrm{PCO}_{2}$ ); the respective regression coefficients were all $\mathrm{r}>0.95$, they were later corrected for pressure and temperature, multiplied by the calibration factor and related per gram dry soil and hour. Weights of respiration vials with soil were taken regularly; tare was subtracted to get rates of drying.

Later in Results and discussion we will consider to what extent the data measured might be biased by diffusion or other transport problems within the soil items, the measured data may then be classified as apparent data (AOCD, $\mathrm{APCO}_{2}$ and $\mathrm{ARQ}$ ).

\subsubsection{Soil (Vs), Air (Va), Pore Volume (Vpo)}

Wet soil was gently pressed before start, there were no fissures between soil and wall of respirometric flask, they appeared however later during drying. We measured them by a series of blades (used in fine mechanics to measure narrow crevices, range 0.05 till $2 \mathrm{~mm}$ ) on four sides of the vial, their mean was subtracted from $\mathrm{r}=2$ $\mathrm{cm}$ to get the radius of the base. The height (he) of the cylinders was estimated using a plate put on the top of the open vial and fixed to center by 4 screws projecting down on the outside of the flask, there were 5 evenly distributed holes on the plate, through which the distance from the top of the plate to soil top was measured by a rod, read by caliper and subtracted from the distance bottom of flask-top of plate. Mean of the 5 readings was height of the soil (he). Final calculation as cylinder volume:

$$
\begin{aligned}
& \text { Soil volume }(\mathrm{Vs}): \mathrm{Vs}=\pi^{*} \mathrm{r}^{2} * \text { he } \\
& \text { Pore volume (porosity) } \mathrm{Vpo}=\mathrm{Vs}-((\mathrm{Vs}-\mathrm{Ws}) / \rho)=\mathrm{Vs}-\left(\left(\mathrm{Vs}-\mathrm{H}_{2} \mathrm{O}\right) / \rho\right)
\end{aligned}
$$

Ws is mass of wet soil.

$$
\text { Volume of air } \mathrm{Va}=\mathrm{Vpo}-\mathrm{H}_{2} \mathrm{O}
$$

\subsection{Experimental}

Changes of GWC in experiment are included as background for other parameters of the soil studied. We refer four principal experiments, which were preceded by several preliminary checks or pilot experiments, all done on one and the same kind of soil collected from one spot. All were aimed towards analysis of changes in soil respiration (OCD, $\mathrm{PCO}_{2}$ and $\mathrm{RQ}$ ) in drying of the soil. The main difference between the experiments was in the amount of soil in flasks and therefore were coded as LS (less soil) and MS (more soil) respectively. Outline of the experiments is in Table 1. Drying proceeded in MS1 and MS2 in two rates, up to about half of the experiments the rate (a) was somewhat faster, then later (rate b). Drying was terminated when oxygen uptake and $\mathrm{CO}_{2}$ production dropped below the sensitivity of the instrument, except LS1 terminated earlier. There were 12 (LS1, MS1) or later 6 (LS2, MS2) parallel respirometers in each series. The basic data differ by an order of magnitude and change during the experiment; therefore we compared the coefficients of variance-cv's. It turned out that the cv's of the means based on six replicates are smaller than those of 12 replicates (Table 2). As standard deviations (second roots of variance) are involved in calculations of the t-test, we consider the data as comparable (Table 2). Weights of vials for GWC estimates were taken not necessarily on the day of respiration measurement. Therefore GWC data for comparison with respiration were interpolated from the respective regression of GWC to time (all $r>0.99$ ).

After each 10 days WHC was estimated in 10 of the vials in the first series (MS1, LS1). In experiment MS2 and LS2 we estimated WHC at the beginning and at termination of the experiment.

Additionally we made a 14-days drying experiment (MP-mud pies) starting at GWC $=1.0$ and finished at 
Table 1. Outline of the experiments.

\begin{tabular}{|c|c|c|c|c|}
\hline & LS1 & LS2 & MS1 & MS2 \\
\hline dry mass [g] mean; se & 3.8; 0.0294 & $3.26 ; 0.025$ & $15.22 ; 0.0751$ & $14.61 ; 0.147$ \\
\hline days of experiment & 24 & 13 & 52 & 42 \\
\hline starts of experiment & Aug 25, 14 & Feb 23, 15 & Nov 11,14 & Feb 23, 15 \\
\hline $1^{\text {st }}$ linear section [d] & 24 & 13 & 32 & 29 \\
\hline${ }^{\circ} \mathrm{C}$ air & $17.2-19.0$ & $18.8-19.7$ & $17.0-18.8$ & $18.4-19.7$ \\
\hline$\beta_{1}$ GWC rate a $[\mathrm{m}]$ & -1.845 & -4.43 & -1.632 & -1.257 \\
\hline$\beta_{1}$ GWC rate b $[\mathrm{m}]$ & $\mathrm{x}$ & $\mathrm{x}$ & -0.721 & -0.412 \\
\hline mud-pies formation [d] & 8 & 6 & 16 & 20 \\
\hline humidity air \% & $50-65$ & 40 & $45-62$ & $40-45$ \\
\hline GWC start & 2.4 & 1.54 & 2.34 & 1.58 \\
\hline GWC end & 0.644 & 0.12 & 0.15 & 0.16 \\
\hline GWC estimates $\mathrm{N}$ & 7 & 5 & 15 & 15 \\
\hline GWC replications & 12 & 6 & 12 & 6 \\
\hline
\end{tabular}

GWC rates are $\beta_{1}$-coefficients in linear regressions per month, a stands for the first, $\mathrm{b}$ for the second linear section. In the LS was one section. LS1 was finished prematurely.

Table 2. Cv's of means of cv's in MS1 and MS2 experiments for OCD, $\mathrm{PCO}_{2}$ and GWC to compare variation in data with 12 or 6 replicates.

\begin{tabular}{cccccc} 
& OCD & $\mathrm{PCO}_{2}$ & GWC & replicates & determinations \\
\hline MS1 & 0.2919 & 0.3581 & 0.1275 & 12 & 14 \\
MS2 & 0.1373 & 0.1401 & 0.0511 & 6 & 13 \\
\hline
\end{tabular}

GWC $=0.13$ at the respiration stop. There were two modes of soil drying, each in six respirometers: a) soil (350 g dry weight) dried freely distributed on a plate, aliquots were taken for each respirometric measurements (per 6 * $5 \mathrm{~g}$ dry weight), returned to the plate and mixed; b) In the second mode wet soil was pressed by hand into the respirometric vials (per $5 \mathrm{~g}$ to each vial), it was left to dry freely between measurements each second day.

We also checked respiration in strict anoxia (SA) comparing respiration of a fresh collected soil with respiration after flushing the respirometers by pure dinitrogen (Air products.com, purity 5.2).

\subsection{Statistics}

Was rather basic, it involved averages = means $(\mathrm{m})$, standard deviations $(\mathrm{s})$, coefficients of variation $(\mathrm{cv})$ and standard errors of the mean (se) calculated for all series of data obtained, referred here or not. Two sided t-test was applied for checks of differences of starting and closing data of series and for checks of differences in neighboring data within series. In final evaluation principal (Table 2) rates were related to month: (30days per month).

This came out from the discrepancy in evaluation of rates in changes in GWC, Vs, Vpo related to day which was our working time unit. We were unable to reject the 0-hypothesis (slope-rate of change of GWC is not different from zero-(from horizontal plane line), whereas paired T-test showed significant differences not only between start and end of experiment $(p<0.001)$, but also between most of neighboring data in the series (Table 3). In general the choice of reference units data is frequently intuitional, comparison of two or more statistical treatments might be a more general tool.

\section{Results and Discussion}

Results are largely based on the four drying experiments specified in Methods, Experimental, Table 1 and in Figure 1. Additionally we performed two checks to get respiration data of the hard mud pies and the small 


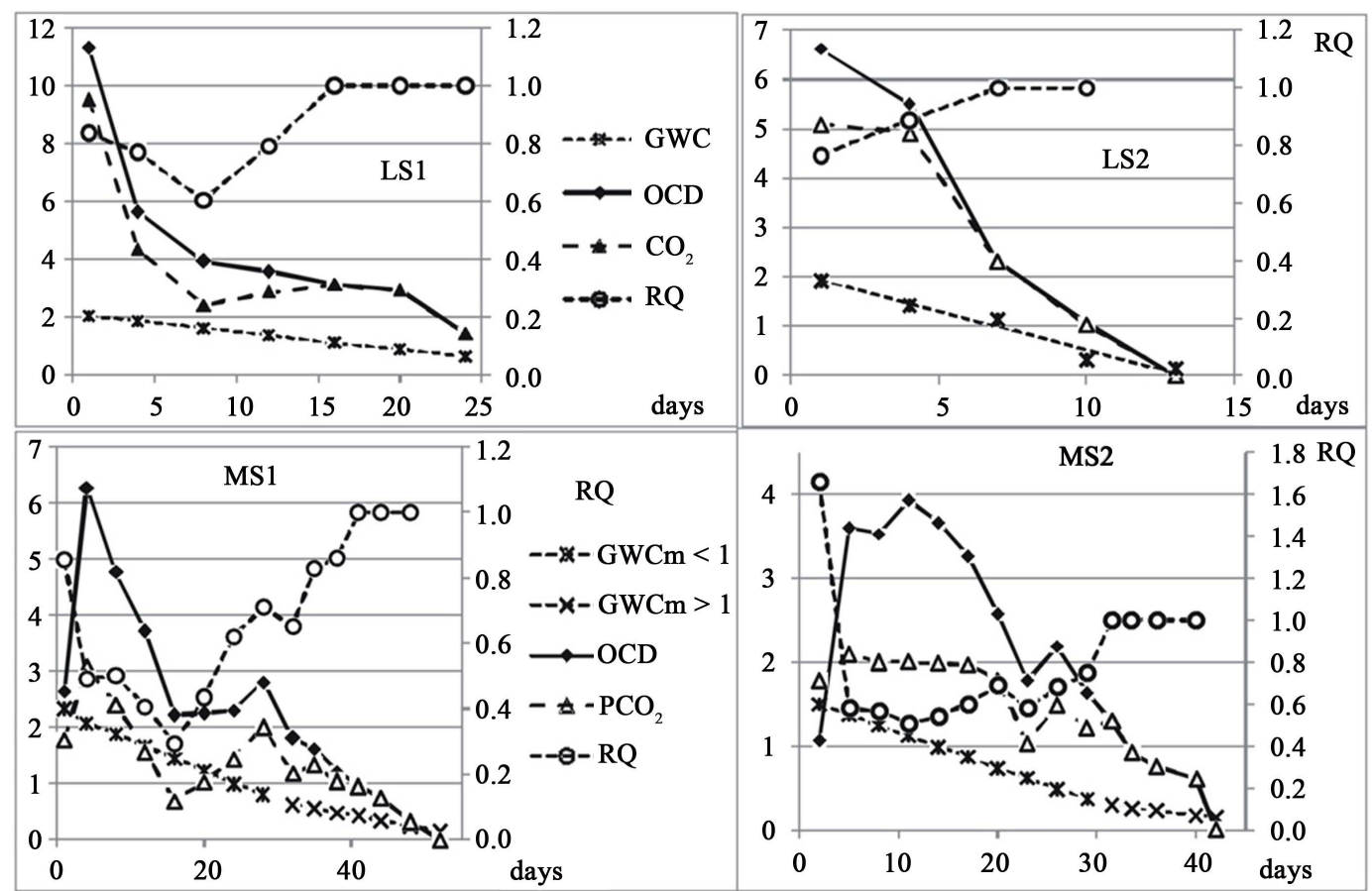

Figure 1. Changes of the gravimetric water content-GWC (as ratios), OCD (oxygen consumption), $\mathrm{PCO}_{2}$ (production of carbon dioxide) — both as $\mu \mathrm{l} \cdot \mathrm{g}[\mathrm{dm}]^{-1} \cdot \mathrm{h}^{-1}$, and RQ (alternative scales) in the four experiments. Rates of changes in GWC are in Table 1 and Table 3, rates of OCD and $\mathrm{PCO}_{2}$ changes as related to GWC are in Table 5, overall budget of the experiments in Table 6. The LS1 experiment was finished before respiration dropped to zero. All standard errors are within the point icons. Specification of symbols for LS2 and MS2 experiments are in parts for LS1 and MS1 respectively.

Table 3. Rates (slopes) GWC, Vs, OCD per week and month for MS2 and LS2 compared to 2-sided t-test for start-end and neighboring days.

\begin{tabular}{|c|c|c|c|c|c|c|c|c|c|}
\hline \multirow{2}{*}{ MS2 } & \multirow{2}{*}{$\beta_{1}$ (slope)/day } & \multirow{2}{*}{$\begin{array}{l}\mathrm{N}=14 \\
\text { all } p\end{array}$} & \multirow{2}{*}{ slopes/month } & \multirow{2}{*}{$p$} & \multirow{2}{*}{$\begin{array}{l}\text { T-test of pairs } \\
\text { start-end }\end{array}$} & \multicolumn{4}{|c|}{ T-test of neighboring days } \\
\hline & & & & & & $p>0.05$ & $p<0.05$ & $p<0.01$ & $p<0.001$ \\
\hline GWC & -0.0361 & $>0.05$ & -1.083 & $<0.005$ & $p<0.001$ & 0 & & 0 & 14 \\
\hline Vs & -0.4255 & $>0.05$ & -12.76 & $<0.001$ & $p<0.001$ & 6 & 5 & 1 & 2 \\
\hline OCD & -0.0733 & $>0.05$ & -2.319 & $<0.001$ & $p<0.001$ & 3 & & 1 & 10 \\
\hline LS2 & \multicolumn{9}{|c|}{$\mathrm{N}=5$ for GWC and Vs; $\mathrm{N}=4$ for OCD } \\
\hline GWC & -0.1138 & $>0.05$ & -3.41 & $<0.005$ & $p<0.001$ & 0 & 0 & 0 & 5 \\
\hline Vs & -0.3963 & $>0.05$ & -11.89 & $<0.001$ & $p<0.001$ & 0 & 0 & 2 & 3 \\
\hline OCD & -0.5904 & $>0.05$ & -17.71 & $<0.001$ & $p<0.001$ & 0 & 1 & 0 & 3 \\
\hline
\end{tabular}

Significance of slopes related to day and month, compared to 2-sided T-test for data pairs start-end of experiment and neighboring pairs during the experiment.

sandy like aggregates and demonstrate $\mathrm{CO}_{2}$ production in strict anoxia. Also we assured us that the hard dry mud pies are not just gypsum or carbonate.

\subsection{Humidity}

Relationships of humidity (GWC) are therefore the first to be examined more in detail. Its changes related to time in terms of days[d] proved to be controversial; this resulted in use of month [m] as time reference unit in some selected relationships (Table 3). 
GWC decreased during the experiments linearly with time for approximately $2 / 3$ of the course, towards the end in the MS experiments, there was a significant drop in rate (Table 1). The course was a single linear function with respect to time in the shorter LS experiments. A slowing of the function is indicated in LS2, there are, however, too few data to get a significant picture (Figure 1).

\subsection{Soil Volume}

So far cracks in dry soils were often referred from the field in the literature, but there was/is much less interest in experiments on changes of soil volume in lab. There are more recent works on the impact of repeated drying and rewetting cycles on characteristic of soils resulting so far in non-complete understanding of these processes. We registered shrinking of soil during LS1 and MS1 experiments and estimated it with assumptions of linearity; nevertheless these estimates for MS1 and LS1 are in good agreement with the data from the second series of experiments. All four experiments have shown significant shrinking and changes of pores (porosity). The LS2 experiment is less successful due to high rate of drying and GWC decrease, therefore it was short and only few data were obtained (Table 2 and Table 3).

Soil humidity (GWC) appears to be the governing parameter in shrinking of soil and respiration of soil biota. Shrinking [soil volume Vs, $\mathrm{cm}^{3}$ ] and volume of calculated pores, both Vpo and Va, are linearly related with GWC, only Va in LS2 is not significant (Table 4). Regressions of Vs to time [d] were significant.

\subsection{Changes of Soil Consistency}

Formation of "mud-pies", hard stone-like concretions of dried soil, occurred in all four experiments. In MS1 and MS2 it begun approximately in 1/4 of the drying time, resulted from shrinking of soil, fissures appeared between soil and the walls of respirometric flasks, thus more of the soil surface was opened to the gas phase in

Table 4. Soil volume (Vs), porosity (Vpo) and air filled porosity (Va), their \% share in Vs, rates of change $\left(\beta_{1}, \mathrm{r}\right)$, probability of no change $(p)$.

\begin{tabular}{|c|c|c|c|c|}
\hline & LS1 & LS2 & MS1 & MS2 \\
\hline Vs; start & 9.79 (d8) & 8.042 & 37.7 (d16) & 32.735 \\
\hline $\mathrm{N}$; se & 9 & 9; 0.33 & 13 & $24 ; 0.509$ \\
\hline Vs end & $8.17(\mathrm{~d} 20)$ & 3.035 & 25.4 & 15.987 \\
\hline se & $\mathrm{x}$ & 0.222 & $\mathrm{x}$ & 0.245 \\
\hline Vs-GWC; $\beta_{1}$ & 1.57 & 3.74 & 7.45 & 11.73 \\
\hline$-\mathrm{r}$ & 0.944 & 0.977 & 0.941 & 0.990 \\
\hline$p<$ & 0.025 & 0.001 & 0.001 & 0.001 \\
\hline$\%$ Vpo in Vs start & 84.2 & 83.2 & 87.5 & 86.38 \\
\hline$\% \mathrm{Vpo}$ in Vs end & 62.3 & 56.5 & 50.1 & 58.32 \\
\hline Vpo-GWC; $\beta_{1}$ & 2.1775 & 3.15 & 10.696 & 13.252 \\
\hline$-\mathrm{r}$ & 0.955 & 0.9947 & 0.995 & 0.8767 \\
\hline$p<$ & 0.001 & 0.001 & 0.001 & 0.001 \\
\hline \%Va in Vs start & 15.18 & 16.13 & 10.3 & 15.13 \\
\hline$\% \mathrm{Va}$ in $\mathrm{Vs}$ end & 36.20 & 41.79 & 45.01 & 68.75 \\
\hline Va-GWC; $\beta_{1}$ & -1.13 & -0.139 & -3.572 & -1.468 \\
\hline$-\mathrm{r}$ & 0.983 & 0.347 & 0.964 & 0.877 \\
\hline$p$ & $<0.001$ & $>0.05$ & $<0.001$ & $<0.001$ \\
\hline
\end{tabular}

Va did not change significantly in drying, ratio to Vs changed just due to decrease of Vs. 
the flasks. The rate of drying was also related to the amount of soil in the flasks. In the MS1 and MS2 series there is a higher soil layer, longer diffusion path and supposed humidity zonation. In the LS series drying and course of the experiments were faster (Table 1); the "mud pies" eventually formed just a narrow plate of dried soil.

All these processes result in increasing access of air into the soil preparation, in a much better ventilation of the dried soils than is in the wet soils and contributed to formation of the "mud pies" during the drying experiments.

It's a common knowledge, that wet soils are soft, pastry; easily adopt form of container under only very slight pressure. When dried they become hard, stone-like, if slightly pressed together before drying; they resist pressures approximately like wall nuts, larger "mud pies" are more resistant than small ones. Sieved soil loosely distributed on a plate acquires in drying a sandy character; its total surface is much greater than that of the "mud pie”.

To check the character of the hardiness of the mud pies we chopped off $5.0 \mathrm{~g}$ material from the top of the $25 \mathrm{~g}$ "mud pie" and took an aliquot of the same weight from the sandy like dried soil. Both were suspended in $50 \mathrm{ml}$ of pure water and extracted for 2 hours and 30 minutes. Both soils looked hydrophobic at the beginning, after approx. 45 minutes they turned more polar. Some air bubbles were attached to dark, presumably light organic soil particles. The extracts were separated from the rests of soils by filtration through Macherey-Nagel filter paper MN $640 \mathrm{~m}$. Both filtrates were yellowish brown, the "mud pie” extract was distinctly darker, but not brown, both very slightly colloidal. Most of the residues remained in the Erlenmeyer's with the heavy sand fraction, much less on the filters. We measured $\mathrm{pH}$, conductivity and redox potential in both extracts: $\mathrm{pH}=4.48$ and 4.53, conductivity = 54 and $116 \mu \mathrm{S} \cdot \mathrm{cm}^{-1}$ in "sand" and "mud pie" respectively, redox was E = $320 \mathrm{mV}$ in both. Addition of $1 \mathrm{ml} 0.2$ molar solution of $\mathrm{BaCl}_{2}$ to each of the extracts did not result in formation of any precipitate. We conclude, that the top of the "mud pie" probably contained more organic matter than "the sandy" fraction (more intense humic coloration of the extract), there was certainly no carbonate nor gypsum formed in the drying soils, could not been responsible for formation of the "mud pies". The two major components of our soil are the postglacial sand, which however remained unchanged in all the procedures as a separate and non-reactive fraction. The second major component is SOM.

We want suggest replacement of H-bonds (water bridges) in wet soil by some other weak interactions (noncovalent bonds) during drying, possibly by hydrophobic weak bonds. A slight pressure and greater mass of wet soil brings soil aggregates closer together and enables formation of other particle interactions when O-(water-) bridges are abolished in drying.

For considerations of bonding within soil aggregates a change in scale of the aggregates might be useful. Remind that there are 6E23 single molecules per each mole (Avogadro number), thus in $1 \mu \mathrm{g}$ of SOM 6E14 molecules of organic compounds of mean molecular mass 1000 may be accommodated. Soil science does not seem to be generally ready for thinking in such scales (unfortunate Table 2.1 in Voroney [22], containing organic molecules $\left[10^{-9} \mathrm{~m}\right]$ larger than viruses, $\Psi>-1500 \mathrm{kPa}$ not only in Chowdhury [13] etc.).

\subsection{Respiration}

\subsubsection{Relationships to GWC}

Relationships of gas exchange $\left(\mathrm{OCD}, \mathrm{PCO}_{2}\right)$ with time and GWC are more complex, the respective regression coefficients are lower compared to regressions of GWC and time; the overall tendency of respiration (OCD and $\mathrm{PCO}_{2}$ ) is a decrease with progressing drying as water is a primary essential-even substrate-of life (Table 5, Figure 1). Data on respiration, both OCD and $\mathrm{PCO}_{2}$, follow common trends: high values immediately at the begin-

Table 5. Regression coefficients $\left(\beta_{1}, \mathrm{r}\right)$ for respiration to GWC.

\begin{tabular}{|c|c|c|c|c|c|c|}
\hline r/GWC & LS1 & LS2 & MS1 all & MS1 after d2 & MS2 all & MS2 after d3 \\
\hline OCD $\beta_{1}$ & -5.104 & -3.612 & -1.970 & -2.560 & -2.000 & -2.950 \\
\hline$r$ & 0.833 & 0.956 & 0.837 & 0.936 & 0.712 & 0.949 \\
\hline $\mathrm{PCO}_{2} \beta_{1}$ & -3.704 & -0.877 & -0.816 & -0.978 & -1.149 & -1.351 \\
\hline$r$ & 0.735 & 0.953 & 0.732 & 0.765 & 0.842 & 0.881 \\
\hline
\end{tabular}

For MS experiments coefficients are for all data and also for dates after d2 and d3 due to the delayed Birch effect. 
ning of experiments in both LS, or after three or five days in the MS series. There is a more or less stable respiration in the central part of the course in MS1 and MS2 (Table 2 and Table 4). Basic statistics of respiration data show small variance, se's in all presented and vast majority of data not shown are within the point icons. The data in figures are of similar magnitude with those published by selected authors for forest soils considering problems in recalculation of area related data to mass related. Butler et al. [8] consider "rainfall as main driver of soil $\mathrm{CO}_{2}$ efflux and its components".

\subsection{2. $\mathrm{CO}_{2}$ Storage}

Distribution coefficient between gas and water for $\mathrm{CO}_{2}$ is very close to one at the temperature of the experiments, storage capacity for $\mathrm{CO}_{2}$ in soil water is therefore equal to GWC * dry mass of soil. It is the volume of water in respirometer (microcosm), about $20 \mathrm{ml}$ in the first days of the MS experiments or $5 \mathrm{ml}$ in the both LS; apparent production in two or three days.

Another estimate of $\mathrm{CO}_{2}$ stored may result from the difference between AOCD and $\mathrm{APCO}_{2}$ during the flush of respiration when soil is still wet, in MS1 days 3 to12. Assuming real RQ $=1.0$ it is $2.81 \mathrm{ml} \mathrm{CO}_{2}$ stored in 28.8 $\mathrm{ml} \mathrm{H}_{2} \mathrm{O}$, the storage capacity is thus used in less than $10 \%$.

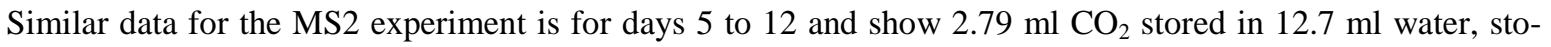
rage capacity used in approximately 22\%. Assuming real $\mathrm{RQ}=0.7$ result in $1.97 \mathrm{ml} \mathrm{CO}_{2}$ stored in $\mathrm{MS} 1$ and 1.95 $\mathrm{ml} \mathrm{CO} 2$ in MS2 respectively. Details of calculations are not shown.

The storage capacity for $\mathrm{CO}_{2}$ was falling in experiments with progressing drying. Angert et al. [23] compared measured data of RQ (ARQ) with soil air analysis showing relatively low $\mathrm{pCO}_{2}$. Their assumption on equilibrium between headspace (soil air) and wet acidic soil might not be fulfilled; there might be physical separation between the sections of the soil gas and the watered section, where $\mathrm{CO}_{2}$ is primarily produced. Also a careful acidification and mixing of a tightly closed dilute solution of bicarbonate without gas phase need not result in production of gas bubbles. This may apply to a wet soil, where $\mathrm{CO}_{2}$ is produced by microorganisms. ARQ data of Angert et al. [23] agree with our RQ in the respiration budget, there is also agreement on denial of carbonate chemistry as cause in the background of $\mathrm{RQ}<1$, we propose oxidation of methane and particularly ethanol produced in fermentation as hypothetic substrates in respiration with $\mathrm{RQ}<1$. We also seem to agree in accent on processes in studies. Sierra and Renault [14] conclude, that production is negligible compared to dissolved $\mathrm{CO}_{2}$, this does not apply to acidic soils $(\mathrm{pH}<4)$, where bicarbonate is practically missing. Therefore we did not consider bicarbonate storage, as estimates in our soil were always $\mathrm{pH}<4.0$. In acid soils however even a small volume stored may result in serious shifts in RQ.

\subsubsection{Anoxia in Soil}

To show gas exchange in strictly anoxic soil we placed $21 \mathrm{~g}$ fresh collected sieved wet soil $(7.3 \mathrm{~g} \mathrm{dm})$ into each of four respirometers. Two of the respirometers were flushed with pure dinitrogen $50 \mathrm{ml} \cdot \mathrm{min}^{-1}$, for 10 minutes; we registered $\mathrm{O}_{2}$ consumption and $\mathrm{CO}_{2}$ production [with and without $\mathrm{NaOH}$ trap inside]. The other pair of respirometers was a control to see regular soil respiration. There were 3.83 and $3.89 \mu \mathrm{l} \cdot \mathrm{g}^{-1}(\mathrm{dm}) \cdot \mathrm{h}^{-1}$ respectively gas produced in the $\mathrm{N}_{2}$ flushed respirometers without the hydroxide trap. There was however no gas production, nor consumption when hydroxide trap was placed in both respirometers; this also shows that the gas produced without the trap is absorbed by hydroxide, it is most probably $\mathrm{CO}_{2}$ and not $\mathrm{CH}_{4}$. $\mathrm{RQ}$ cannot be determined as shown in Introduction. The regular respiratory control in the second pair of respirometers provided 8.92 and $8.56 \mu \mathrm{l} \mathrm{O}{ }_{2} \cdot \mathrm{g}^{-1}(\mathrm{dm}) \cdot \mathrm{h}^{-1}$ respectively and $4.51 \mu \mathrm{CO}_{2} \cdot \mathrm{g}^{-1}(\mathrm{dm}) \cdot \mathrm{h}^{-1}$ in both respirometers, this is consistent with data in Figure 1.

\subsubsection{Respiration and Size of "Mud Pies"}

Another pilot experiment aimed to differences of respiration in highly dried soils as "mud pies" or small sandy like aggregates. In the "mud pies" both $\mathrm{OCD}$ and $\mathrm{PCO}_{2}$ are some $20 \%$ lower than in the sandy sieved small aggregates. Fast drops of simultaneous decrease of OCD and $\mathrm{PCO}_{2}$ by approximately $0.6-0.8 \mu \mathrm{l} \cdot \mathrm{g}^{-1} \cdot \mathrm{h}^{-1}$ occurred at 0.63 GWC in "mud pies", at 0.43 in "sand". Drying in "mud pies" and associated decrease of respiration is slower in "mud pies". There is no contradiction to Figure 1.

\subsection{5. "Birch Effect"}

High respiration data occurring after changed conditions (sieving, watering...) are referred as the Birch effect 
[24]. In our experiments it occurred in LS1 on d1, in MS1 on d 5 - 14 and also at lower GWC $=1.41$ starting value in LS2 and MS2 thus at a somewhat lower moisture throughout the drying experiment (Figure 1). The delayed respiration flush in both MS experiments resulted in distorsions of the relationships of respiration to GWC, this was overcome by skipping the $\mathrm{d} 1$ or $\mathrm{d} 2$ data from the relationships in MS2 and MS1 (Table 6). The delay of flush in both MS experiments was probably caused by pressing the greater amount of soil at start resulting in formation of solid "mud pies", while the small amounts of soil in both LS resulted in a thin layer of soil with minor limitation in gas traffic in the first days. The slightly smaller humidity in MS2 compared to MS1 was of minor importance in this range. We however feel that the impression of extraordinarily of high starting RQ's in MS2 is partly misleading, it comes rather from general characteristics of ratios; OCD and $\mathrm{PCO}_{2}$ data are of similar magnitude (1.78 and 1.07 respectively), not strikingly different indeed.

High flushes of respiration following change of conditions are debated for last 50 years [24]. So far they were attributed to increased availability of respiration substrates from organisms which died in preceding dries, even if the drop in water content was small [25] or to repeated drying and rewetting (e.g. [26]) or simply to watering of soil (e.g. [13]). Even the detailed study by Unger [27] which includes interaction of soil and the vegetation using highly advanced methodology does not seem to be the last word in the debate. Flush took place in all four experiments in fresh and sieved samples, but not watered, of course sampling was at the very beginning (Figure 1, Table 5, first section of the course). Respiration decreased dramatically in the next readings. Therefore we want to propose a hypothesis not relying primarily on the experimental conditions, but rather on the organisms themselves: Before the collection of soil organisms were adapted to low respiration rates in their natural settings, supplemented by fermentation. Sieving (or in other papers published-water added) allows more air to enter the soil; previously accumulated $\mathrm{CO}_{2}$ is released to air or absorbed in water. The overall tendency during the experiments is decrease of $\mathrm{AOCD}$ and $\mathrm{APCO}_{2}$ with decreasing GWC, the data of the first part of experiments are however influenced by $\mathrm{CO}_{2}$ produced and stored in soil water and $\mathrm{Va}$ available, at this stage it was not included in the changes of gas contents measured. Some loss of humidity (GWC) in sieving is highly probable. Soil biota may require time to adapt to available dioxygen, presumably by activation/reconstruction of respiratory mechanisms (e.g. enzyme complexes of oxidative phosphorylation pathway) which appear to be of small use in more enzyme copies in wet soils in natural settings with limited oxygen availability.

\subsubsection{Summing up OCD and $\mathrm{PCO}_{2}$ in the Process}

Summed OCD and $\mathrm{PCO}_{2}$ for the whole drying experiment showed in all four experiments RQ around 0.7 (Table 6). $\Sigma R Q$ is somewhat higher in the faster drying experiments (LS), suggesting less hypoxia. This may support the hypothesis presented in introduction on a mixed status of organisms in wet soils, respiration contemporarily with fermentation and use of the fermentation products (e.g. ethanol) as substrates in respiration when $\mathrm{O}_{2}$ becomes available.

Studies of some process which take into account all data, characterizing the variable soil condition during a process may provide more information, than short measurements or flashes of soil metabolism in \pm constant conditions. Type of instrumentation may be of secondary importance only-modern methods of $\mathrm{O}_{2}$ estimation are used only exceptionally [27].

Nevertheless if there is $\mathrm{O}_{2}$ consumption, anoxia is not in the total mass of soil, possibly in a limited area in center of the soil bloc.

\subsubsection{Respiration Ends at Limiting GWC}

There is a small, but significant peak of respiration in at the beginning of the decreasing phase at $\mathrm{d} 26$ in MS1; in MS2 at d 26. A similar peak was registered by Thomson et al. [10] on the 5-th day of their 7-days experiment,

Table 6. Sums of OCD, COP, and $\Sigma R Q$ in four experiments [ml].

\begin{tabular}{|c|c|c|c|c|}
\hline & LS1 & LS2 & MS1 & MS2 \\
\hline$\Sigma \mathrm{OCD}$ & 7.67 & 15.14 & 42.53 & 33.13 \\
\hline$\Sigma \mathrm{COP}$ & 6.31 & 13.14 & 23.97 & 22.41 \\
\hline$\Sigma \mathrm{RQ}$ & 0.82 & 0.87 & 0.56 & 0.68 \\
\hline
\end{tabular}

$\Sigma$ RQ is the ratio of the two sums. Duration of experiments in Table 3. 
which did not continue to a respiration stop. We propose to interpret as increased respiration due to increasing access of air to the drying soil, in our experiments shortly overrun but proceeding desiccation of the soil and confirmed by fast drops afterwards.

All four series (including the prematurely finished LS1) end up with RQ = 1 when GWC is approximately $=1$ in LS experiments, but GWC $\approx 0.6$ in MS (Figure 1 ).

$\mathrm{CO}_{2}$ retained in the first section of experiments in water is completely aerated from the soil towards the end when soil is very dry; when respiration seizes at GWC ca 0.15 , there is no measurable $\mathrm{PCO}_{2}$, as is no OCD.

All drying experiments were terminated when GWC dropped to 0.15 and respiration stopped. The experiment LS1 was in fact finished prematurely, nevertheless its final RQ $=1$. Also in a preliminary experiment not reported here (summer 2014) respiration (both $\mathrm{OCD}$ and $\mathrm{PCO}_{2}$ ) seized at GWC $=0.15$ and $\mathrm{RQ}=1$. The respiration limit at GWC $=0.15$ need not be a universal value for many soils, Chowdhury et al. [13] reported respiration in Australian soils at recalculated GWC $=0.025$.

\section{Conclusions}

There is a distinct peak of respiration rate at the beginning of the experiment (Birch effect); it occurred with some delay in the larger soil blocks. The effect was not associated with increased humidity, rather with increased availability of oxygen within the soil; therefore we suggest interpreting as reaction of the enzymatic systems of the soil organisms. The respiration rate decreased linearly with decreasing humidity of the soil; RQ dropped below 0.5 in both larger soil blocks for some time; reason is evidently in storage of $\mathrm{CO}_{2}$ produced in soil water. Rate of respiration registered is also related to consistency of soil; hard "mud pies" respire some $20 \%$ less than the small aggregates of sandy character.

Respiration ceased when GWC dropped down to 0.15. RQ was increasing in the second part of the experiments; a few days before the end it reached 1.00 and remained so till the last moment. We think it comes from $\mathrm{CO}_{2}$ stored in the earlier parts of the drying process which is aerated when amount of water within the soil decreased and air in soil got higher. $\Sigma$ RQ for the whole budget of the experiments is about 0.7 ; it is somewhat higher for the smaller soil items (LS) suggesting less hypoxia and may be consistent with partial use of fermentation products like ethanol $(\mathrm{RQ}=0.57)$.

\section{References}

[1] Davidson, E.A., Savage, K., Verchot, L.V. and Navarro, R. (2002) Minimizing Artifacts and Biases in Chamber-Based Measurements of Soil Respiration. Agricultural and Forest Meteorology, 113, 21-37. http://dx.doi.org/10.1016/S0168-1923(02)00100-4

[2] Luo, Y. and Zhou, X. (2010) Soil Respiration and the Environment. Academic Press, Burlington.

[3] Luan, J., Liu, S., Zhu, X., Wang, J. and Liu, K. (2012). Roles of Biotic and Abiotic Variables in Determining Spatial Variation of Soil Respiration in Secondary Oak and Planted Pine Forests. Soil Biology and Biochemistry, 44, $143-150$. http://dx.doi.org/10.1016/j.soilbio.2011.08.012

[4] Ilstedt, U., Nordgren, A. and Malmer, A. (2000) Optimum Soil Water for Soil Respiration before and after Amendment with Glucose in Humid Tropical Acrisols and a Boreal Mor Layer. Soil Biology \& Biochemistry, 32, 1591-1599.

[5] Campbell, N.A. (1993) Biology. 3rd Edition, Benjamin/Cummings, Francis Group, Redwood City.

[6] Alberts, B. and Johnson, A. (2002) The Molecular Biology of the Cell. Garland, Taylor and Francis Group, New York.

[7] McGill, W.B. (2007) The Physiology and Biochemistry of Soil Organisms. In: Paul, E.A., Ed., Soil Microbiology Ecology, and Biochemistry, 3rd Edition, Academic Press, Burlington. http://dx.doi.org/10.1016/b978-0-08-047514-1.50013-5

[8] Butler, A., Meir, P., Saiz, G., Maracahipes, L., Marimon, B.S. and Grace, J. (2012) Annual Variation in Soil Respiration and Its Component Parts in Two Structurally Contrasting Woody Savannas in Central Brazil. Plant Soil, 352, 129142. http://dx.doi.org/10.1016/b978-0-08-047514-1.50013-5

[9] van Suchtelen, H. (1910) Uber die Messung der Lebenstätigkeit der aerobiotischen Bakterienim Boden durch die Kohlensaureproduktion. Centrablattfür Bakteriologie, 28, 46-89. Cited from: Lundegardh, H. (1926) Carbon Dioxide Evolution of Soil and Crop Growth. Soil Science, 23, 417-453.

[10] Thomson, B.C., Ostle, N.J., McNamara, N.P., Whiteley, A.S. and Griffith, R.I. (2010) Effects of Sieving, Drying and Rewetting upon Soil Bacterial Community Structure and Respiration Rates. Journal of Microbiological Methods, 83, 69-73. 
[11] Gaumont-Guay, D.T., Black, T.A., Tim, J., Griffis, T.J., Alan, G., Barr, A.G., Jassal, R.S. and Nesic, Z. (2006) Interpreting the Dependence of Soil Respiration on Soil Temperature and Water Content in a Boreal Aspen Stand. Agricultural and Forest Meteorology, 140, 220-235. http://dx.doi.org/10.1016/j.agrformet.2006.08.003

[12] Walker, T.S., Harsh, P.B., Grotewold, E. and Vivanco, J.M. (2003) Update on Root Exudation and Rhizosphere Biology. Plant Physiology, 132, 44-51. http://dx.doi.org/10.1104/pp.102.019661

[13] Chowdhury, N., Burns, R.G. and Marschner, P. (2011) Recovery of Soil Respiration after Drying. Plant Soil, 348, 269279. http://dx.doi.org/10.1007/s11104-011-0871-2

[14] Sierra, J. and Renault, P. (1995) Oxygen Consumption by Soil Microorganisms as Affected by Oxygen and Carbon Dioxide Levels. Applied Soil Ecology, 2, 175-184. http://dx.doi.org/10.1016/0929-1393(95)00051-L

[15] Jenkins, M.E. and Adams, M.A. (2011) Respiratory Quotients and Q10 of Soil Respiration in Sub-Alpine Australia Reflect Influences of Vegetation Types. Soil Biology \& Biochemistry, 43, 1266-1274. http://dx.doi.org/10.1016/j.soilbio.2011.02.017

[16] Araujo, A.S.F., Cesarz, S., Leite, L.F.C., Borges, C.D., Tsai, S.M. and Eisenhauer, N. (2013) Soil Microbial Properties and Temporal Stability in Degraded and Restored Lands of Northeast Brazil. Soil Biology \& Biochemistry, 55, 175-181. http://dx.doi.org/10.1016/j.soilbio.2013.07.013

[17] Lamy, E., Tran, T.C., Mottelet, S., Pauss, A. and Schoefs, O. (2013) Relationships of Respiratory Quotient to Microbial Biomass and Hydrocarbon Contaminant Degradation during Soil Bioremediation. International Biodeterioration \& Biodegradation, 83, 85-91. http://dx.doi.org/10.1016/j.ibiod.2013.04.015

[18] Blazka, P. and Fischer, Z. (2014) Moisture, Water Holding, Drying and Wetting in Forest Soils. Open Journal of Soil Science, 4, 174-184. http://dx.doi.org/10.4236/ojss.2014.45021

[19] Carter, M.R. and Gregorich, E.G., Eds. (2008) Soil Sampling and Methods of Analysis. CRC Press, Taylor \& Francis Group, Boca Raton.

[20] Grace, C., Hart, M. and Brookes P.C. (2006) Laboratory Manual of the Soil Microbial Biomass Group. Rothamsted Research.

[21] Priha, O. and Smolander, A. (2003) Short-Term Uptake of ${ }^{15} \mathrm{NH}_{4}$ into Soil Microbes and Seedlings of Pine, Spruce and Birch in Potted Soils. Biology and Fertility of Soils, 37, 324-327.

[22] Voroney, R.P. (2007) The Soil Habitat. In: Paul, E.A., Ed., Soil Microbiology Ecology and Biochemistry, 3rd Edition, Elsevier, Academic Press, London, 25-49. http://dx.doi.org/10.1016/b978-0-08-047514-1.50006-8

[23] Angert, A., Yakir, D., Rodeghiero, M., Preisler, Y., Davidson, E.A. and Weiner, T. (2014) Using $\mathrm{O}_{2}$ to Study the Relationships between Soil $\mathrm{CO}_{2}$ Efflux and Soil Respiration. Biogeosciences Discussions, 11, 12039-12068. http://dx.doi.org/10.5194/bgd-11-12039-2014

[24] Birch, H.F. (1964) Mineralisation of Plant Nitrogen Following Alternate Wet and Dry Conditions. Plant Soil, 20, $43-49$. http://dx.doi.org/10.1007/BF01378096

[25] Fischer, T. (2009) Substantial Rewetting Phenomena on Soil Respiration Can Be Observed at Low Water Availability. Soil Biology \& Biochemistry, 41, 1577-1579. http://dx.doi.org/10.1016/j.soilbio.2009.04.009

[26] Shi, A. and Marschner, P. (2014) Drying and Rewetting Frequency Influences Cumulative Respiration and Its Distribution over Time in Two Soils with Contrasting Management. Soil Biology \& Biochemistry, 72, 172-179. http://dx.doi.org/10.1016/j.soilbio.2014.02.001

[27] Unger, S., Maguas, C., Pereira, J.S., David, T.S. and Werner, C. (2012) Interpreting Post-Drought Rewetting Effects on Soil and Ecosystem Carbon Dynamics in a Mediterranean Oak Savannah. Agricultural and Forest Meteorology, 154155, 9-18. http://dx.doi.org/10.1016/j.agrformet.2011.10.007 